\title{
Sustentabilidade: um olhar sobre a relação homem natureza
}

\section{Alecksandra Vieira de Lacerda}
Centro de Desenvolvimento Sustentável do Campina Grande. Sumé-PB.
Semiárido.
Federal de
Brasil.
(CEP
58540-000).

E-mail: alecvieira@yahoo.com.br.

Resumo. As reflexões teóricas aqui apresentadas estão centradas na concepção sistêmica do desenvolvimento sustentável. Neste cenário, trabalhou-se a concepção que as atividades humanas devem integrar o meio natural considerando, portanto, a visão holística e intimamente relacionada com as características físicas do ambiente. Assim, o objetivo deste artigo é a geração de uma base de conhecimento sobre a qual deverão ser edificados conceitos, estratégias e abordagens para ocupar áreas que se constituem em lacunas na compreensão da relação do homem com a natureza. Nesse sentido, o acervo teórico delineado mostra-se em bases contextualizadas, contribuindo para a percepção do bem natural e humano, sem a sua separação no tempo, no espaço e principalmente sem a separação dos fatores de dependência destes componentes nos sistemas naturais. Portanto, o olhar lançado permite definir a essência do desenvolvimento e da sustentabilidade no meio constituído de conexões múltiplas e complexas.

Palavras-chave: Responsabilidade ambiental; Economia sustentável; Justiça social.

\begin{abstract}
Sustainability: a new look at the relationship between man and nature. The theoretical reflections presented here are centered on the systemic conception of sustainable development. In this scenario, we worked on the concept that human activities should integrate the natural environment, considering a holistic view as closely related to the physical characteristics of the environment. Thus, the objective of this article is the generation of foundational knowledge upon which new concepts, strategies and approaches must be built to occupy areas which are lacking in their understanding of the relationship between man and nature. In this sense, the delineated theoretical collection is based contextualized foundations, contributing to the perception of the human and natural good, without separation in time and space, and principally without separation of such dependent factors from the components of their natural systems. Therefore, the proposed view allows definition of the essence of development and sustainability in an environment constituted of multiple and complex connections.
\end{abstract}

Keywords: Environmental responsibility; Sustainable economy; Social justice.
Recebido: 15/06/2017

Aceito:

24/06/2017

Publicado:

30/06/2017

Acesso Aberto Artigo completo

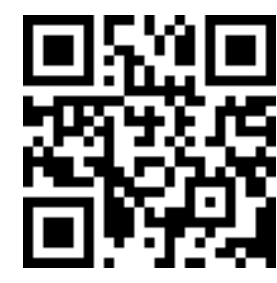

ORCID

(1) 0000-0002-9703-3997

Alecksandra Vieira de Lacerda 
As marcas que definem e traduzem a relação do homem com a natureza ao longo do processo evolutivo permitem observar que desde tempos imemoriais, 0 ser humano luta pela sua sobrevivência, modelando o meio físico ou consumindo seus recursos naturais, numa infinita busca por riqueza e bem-estar material. Assim, registra-se que a humanidade sempre interagiu de forma complexa com a biosfera, modificando habitats e impondo novos desafios às atuais e futuras gerações (Pacheco et al., 2014). Portanto, sob o pretexto do crescimento econômico, os processos de modernização vêm trazendo graves desequilíbrios socioambientais a diversas regiões do Planeta, que ratifica a necessidade de adotar-se urgentemente novos modos de desenvolvimento que assumam como essência os preceitos da sustentabilidade (Pacheco et al., 2006).

Acompanhando essa linha de raciocínio, observa-se que a relação do homem com a natureza assume posição mais agressiva à medida que as comunidades progridem na acumulação de conhecimentos e em sua organização (Lima, 1995). Esse processo está vinculado à necessidade que o homem sente de explorar a natureza com o propósito de torná-la mais útil a sua sobrevivência, ou seja, de dominá-la. Assim, ao longo do processo de evolução, o meio ambiente é a peça central que o homem procura modificar em benefício próprio (Lima, 1995). Isto é ratificado quando se observa que o ser humano, dentro do processo de evolução, dominou os mares, conquistou novas terras, desenvolveu a ciência e a técnica, inventou a máquina, construiu a fábrica e gerou uma civilização caracterizada pelo constante crescimento econômico e tecnológico (Milaré, 1995).

A incorporação dessa postura de dominação sobre o meio natural fez com que o homem civilizado se defrontasse com problemas advindos da destruição dos recursos naturais em proporções nunca imaginadas. Isto é observado por (Cavalcanti, 1998) ao mencionar que este crescimento, sob as formas em que é compreendido, conduz sempre a algum tipo de agressão contra o ambiente. Nesse sentido, para este autor, os esforços presentes visando ao progresso material e mesmo a maneira de satisfação das necessidades básicas do homem no mundo de hoje, mostram-se simplesmente insustentáveis. No meio humano tem-se o aumento da exploração de recursos naturais em níveis sem precedentes (Kates et al., 2001). Diante desta postura, tem-se ressaltado o capitalismo, onde os processos de produção não são projetados de acordo com os desejos e necessidades dos produtores, considerações ecológicas ou sociais, mas de acordo com a lei do valor (Cunha, 2015).

Assim, no estágio atual, as necessidades energéticas, dentro dos processos do homem tecnológico, são tão grandes que o esgotamento de algumas delas poderá ser visualizado em breve e isso se deve ao fato de que, na época atual, os incrementos em demandas energéticas são significativamente grandes e o tempo para suprir estas demandas é muito curto, comparando-se com os tempos de criação e renovação da energia (Carmona, 1986). Neste cenário, a ação desordenada e intensiva dos seres humanos sobre 0 ambiente vem rompendo elos e simplificando os sistemas ecológicos colocando em risco a sua própria existência na Terra. Portanto, é preciso estimular a discussão e a compreensão crítica da crise socioambiental (Lima, 2003).

Diante deste contexto mundial, torna-se imperioso garantir a existência dos recursos necessários à vida no planeta, o que exige a criação de manejos inteligentes e planejamentos racionais no intuito de evitar a degradação, em curto, médio e longo prazo, dos recursos existentes, ou seja, existe a necessidade de incorporação de práticas de desenvolvimento, cuja sustentabilidade viabilize a continuidade de um mínimo de diversidade das formas de vida no planeta (Viertler, 1999). Neste sentido, tem-se presente que o conceito de sustentabilidade equivale à ideia de manutenção de nosso sistema de suporte da vida, significando, pois, o comportamento que procura obedecer às leis da natureza (Cavalcanti, 1998). Assim, Cavalcanti (1998) considera que se trata basicamente 
da percepção do que é biofisicamente possível em uma perspectiva de longo prazo.

O delineamento desses pensamentos só vem corroborar a necessidade de convergir a discussão entre o imperativo do desenvolvimento e os preceitos da sustentabilidade, dentro da agenda de atividades humanas. Nesse sentido, Barbosa e Fernandes (2016) lembram que é importante que todas as nações atuem de forma conjunta para proteger o meio ambiente. A justificativa disso tem como base o fato de que com um ambiente ecologicamente equilibrado, não apenas haverá a preservação de milhões espécies, mas também serão evitados diversos problemas ambientais que prejudiquem os ecossistemas, bem como preservará o bem-estar humano por meio do desenvolvimento sustentável.

A Comissão Mundial sobre Meio Ambiente e Desenvolvimento (CMMAD), conhecida como Comissão Brundtland, da Organização das Nações Unidas (ONU), em 1987, no relatório "Nosso Futuro Comum" (CMMAD, 1991), definiu desenvolvimento sustentável como aquele que atende às necessidades do presente sem comprometer a possibilidade das gerações futuras de atenderem as suas próprias necessidades (Barbieri, 2005).

De acordo com Queiroz (1997), o desenvolvimento contemporâneo tem que viabilizar a integração das várias dimensões da realidade econômica, política, social, cultural, ambiental, tecnológica e institucional. Este autor também descreve que a proposta da sustentabilidade do desenvolvimento deve representar antes de tudo, a compreensão dos limites e ritmos próprios da natureza e a necessidade de contemplar os processos de reprodução dos ecossistemas como variável endógena e intrínseca ao estilo de desenvolvimento.

O desenvolvimento não será sustentável se criar restrição à capacidade de autoreprodução dos ecossistemas e promover a deterioração dos recursos naturais e do meio ambiente, pelo que ele representa em qualidade de vida para a população e em possibilidade de continuidade no tempo dos processos econômicos e sociais (Queiroz,
1997). Assim, o desenvolvimento tenderá à insustentabilidade se não conseguir elevar as condições de vida da população de forma equilibrada, com equidade social, expressa na redução das desigualdades sociais e espaciais. A proposta de desenvolvimento sustentável, de acordo com Miranda et al. (2010), encerra, portanto, três formas diferentes de solidariedade: a solidariedade entre gerações, de modo que o bem-estar das gerações atuais não se efetive em ameaça ao bem-estar das gerações futuras; solidariedade entre os segmentos sociais da mesma geração, que deve promover a redução das desigualdades e a equidade social; e por último a solidariedade entre regiões/nações de modo que a sustentabilidade de um determinado espaço não se traduza na transferência dos elementos de insustentabilidade para outras.

Para Lemos (1996) o desenvolvimento sustentável está baseado no uso racional e eficaz dos recursos naturais, sendo necessária a valorização das diferenças locais e regionais, para utilizar de forma inteligente suas vantagens competitivas para a produção de bens e serviços. Assim, ainda de acordo com Lemos (1996), não será possível a transferência puramente mecânica de experiências que tiveram êxito em locais com condições ambientais, econômicas, sociais e culturais diferentes. A estratégia deve partir de uma abordagem integral e integrada à realidade, articulando ações nos diferentes planos e segmentos complexos, e ainda nos elementos centrais do estilo de desenvolvimento (Queiroz, 1997).

Compondo estas estratégias estão as novas regras econômicas, que na verdade são uma necessidade, se a sustentabilidade do desenvolvimento for confirmada como um objetivo econômico mais consensual e nesse sentido deve ter a consciência de que em lugar de pedir sempre mais consumo, o que se deve ter em vista é o consumo que pode ser levado adiante sustentavelmente (Cavalcanti, 1998).

Por tudo isso, pode-se afirmar que a transição na direção do desenvolvimento sustentável será um processo essencialmente dinâmico, um sempre contínuo processo de tentativas e erros, mudanças e 
adaptações, através de aproximações sucessivas (Lemos, 1996). Isto porque se está falando de atender às necessidades e aspirações de todas as pessoas que habitam este planeta, tanto agora quanto no futuro. O maior desafio será então como criar e manter a vontade política necessária para converter o conceito de desenvolvimento sustentável em ações, que vão significar mudanças consideráveis para toda a sociedade (Lemos, 1996). Ainda de acordo com Lemos (1996), o requisito fundamental para que os países em desenvolvimento possam sonhar em atingir o desenvolvimento sustentável é a melhoria da educação em todos os níveis, acompanhada pela criação e manutenção de uma base endógena adequada em ciência e tecnologia.

De acordo com Brown et al. (1990) o espelho que deve orientar o homem com esse propósito é a natureza, a homeostase, a parcimônia termodinâmica, as quais correspondem a um estilo de vida severo, austero, sóbrio. Para Lemos (1996) uma das questões principais que se terá que resolver, para um futuro melhor, é preservar a base ambiental para o desenvolvimento sustentável, o qual será necessário reduzir drasticamente os impactos negativos provocados nos solos, nos recursos hídricos, nas florestas nativas e na biodiversidade. Entretanto, os atuais Sistemas de Contabilidade Nacional (e.g. Produto Interno Bruto) não trazem uma reflexão adequada sobre o esgotamento e a degradação dos recursos naturais e do meio ambiente.

A utilização de metodologias de contabilidade ambiental, como o Sistema para Contabilidade Econômica e Ambiental Integrada, desenvolvido pelo Escritório de Estatística das Nações Unidas, é um importante instrumento para ajudar os países em desenvolvimento a atingir o desenvolvimento sustentável, por apresentar resultados de acordo com os procedimentos de valorização econômica da natureza (May et al., 2010). Reduzir a emissão de gases que promovam o aquecimento global intensificado, através do uso de sistemas de incentivos e penalidades, com o intuito de promover melhor eficiência energética, 0 desenvolvimento de alternativas para substituir os combustíveis de origem fóssil e o desenvolvimento de tecnologias industriais mais limpas, são metas importantes para se alcançar o desenvolvimento sustentável.

Portanto, o desafio imposto é exercitar a ecossustentabilidade, cujo conceito apresentado por Lacerda (2016), é pautado pelos princípios que buscam respeitar os fatores de resistência e resiliência do meio natural, disponibilizando o uso dos bens naturais sem comprometer a sua existência atual e futura nos sistemas ecológicos, garantindo, assim, o equilíbrio sistêmico através da permanência e renovação dos valores funcionais que são resultantes da relação entre os componentes biológicos, físicos e climáticos.

\section{Declaração de conflito de interesses}

de interesses.

A autora declara não haver conflito

\section{Referências}

Barbieri, J. C. Desenvolvimento e meio ambiente: as estratégias de mudanças da agenda 21. 7. ed. Petrópolis: Vozes, 2005.

Barbosa, E. U. G.; Fernandes, H. F. A planificação do Mundo e suas consequências. Gaia Scientia, v. 10, n. 4, p. 625-636, 2016. https://dx.doi.org/10.21707/gs.v10.n04a47

Brown, L.; Flavin, C.; Postel, S. Picturing a sustainable society. In: Brown, L. R.; Durning, A.; Flavin, C.; French, H.; Jacobson, J.; Lowe, M.; Postel, S.; Renner, M.; Starke, L.; Young, J. (Orgs.). State of the World. Nova York: Norton, 1990. p. 173-190.

Carmona, H. Viabilidade de um tratamento hidro-florestal inter-institucional e inter-disciplinar dentro das bacias hidrográficas. Anais do Simpósio sobre Caatinga e sua Exploração Racional, Feira de Santana, 1984. Brasília-DF: $\quad$ EMBRAPA-DDT, 1986. p. 293-313.

Cavalcanti, C. Sustentabilidade da economia: paradigmas alternativos de realização econômica. In: Cavalcanti, C. (Org). Desenvolvimento e Natureza: estudos para uma sociedade sustentável. 2. ed. São Paulo: Cortez, Recife: Fundação Joaquim Nabuco, 1998. p. 153-174. 
CMMAD - Comissão Mundial sobre Meio Ambiente e Desenvolvimento. Nosso Futuro Comum. 2. ed. Rio de Janeiro: Editora da Fundação Getúlio Vargas, 1991. Disponível em: <http://www.onu.org.br/rio20/img/2012/01/N87 18467.pdf>. Acesso em: 29 abr. 2017.

Cunha, D. O Antropoceno como fetichismo. Revista Continentes, n. 6, p. 83-101, 2015. Disponível em: <http://www.revistacontinentes. com.br/continentes/index.php/continentes/articl e/view/72>. Acesso em: 29 abr. 2017.

Kates, R. W.; Clark, W. C.; Corell, R.; Hall, J. M.; Jaeger, C. C.; Lowe, I.; McCarthy, J. J.; Schellnhuber, H. J.; Bolin, B.; Dickson, N. M.; Faucheux, S.; Gallopin, G. C.; Gruebler, A.; Huntley, B.; Jäger, J.; Jodha, N. S.; Kasperson, R. E.; Mabogunje, A.; Matson, P.; Mooney, H.; Moore III, B.; O’Riordan, T.; Svedin, U. Sustainability science. Science, v. 292, p. 641642, 2001. https://dx.doi.org/10.1126/science. 1059386

Lacerda, A. V. Os cílios das águas: espaços plurais no contexto do Semiárido brasileiro. Campina Grande: EDUFCG, 2016.

Lemos, H. M. Desenvolvimento sustentável. Brasília: Instituto Brasileiro do Meio Ambiente e dos Recursos Naturais Renováveis, 1996. (Série Meio Ambiente em Debate, 3).

Lima, G. C. O discurso da sustentabilidade e suas Implicações para a Educação. Ambiente \& Sociedade, v. 6, n. 2, p. 99-119, 2003. https://dx.doi.org/10.1590/S1414753X2003000300007

Lima, M. J. A. Ecologia Humana: realidade e pesquisa. 2. ed. Recife: Imprensa da UFRPE, 1995.

May, P., Lustosa, M. C., Vinha, V. Economia do meio ambiente. 2 ed. Rio de Janeiro: Elsevier, 2010.
Milaré, E. Política ambiental brasileira. In: Tauk-Tornisielo, S. M.; Gobbi, N.; Foresti, C.; Lima, S. T. (Orgs.). Análise ambiental: estratégias e ações. São Paulo: Fundação Salim, 1995. p. 15-18.

Miranda, C.; Guimarães Neto, L.; Buarque, S. B.; Araújo, T. B. Planejando o desenvolvimento sustentável: a experiência recente do Nordeste do Brasil. Brasília: IICA, 2010.

Pacheco, A. P.; Freire, N. C. F.; Borges, U. N. A trandisciplinaridade da desertificação. Geografia, v. 15, n. 1, p. 5-34, 2006. Disponível em: <http://www.uel.br/revistas/uel/ index.php/geografia/article/view/6598/5999>. Acesso em: 29 abr. 2017.

Pacheco, A. P.; Lucas, A. A.; Silva, B. B.; Mariano, G. Desertificação: contextualização e sensoriamento remoto. Estudos Geológicos, v. 24, n. 2, p. 109-126, 2014. Disponível em: $<$ https://www.ufpe.br/estudosgeologicos/pagina s/edicoes/2014242/2014242t08.pdf>. Acesso em: 29 abr. 2017.

Queiroz, G. S. Plano de Desenvolvimento Sustentável do Rio do Grande do Norte. In: Simpósio Brasileiro Sobre Meio Ambiente e Desenvolvimento Sustentável do Semi-Árido, 1, 1997, Mossoró. Anais... Mossoró: ETFRN/UNED, 1997. p. 142-160.

Viertler, R. B. A ideia de "sustentabilidade cultural”: algumas considerações críticas a partir da Antropologia. In: Bastos Filho, J. B.; Amorin, N. F. M.; Lages, V. N. (Org.). Cultura e desenvolvimento: a sustentabilidade cultural em questão. Maceió: Ed. Universitária/UFPE, 1999. p. 17-35.

Informação da Licença: Este é um artigo Open Access distribuído sob os termos da Licença Creative Commons Attribution, que permite uso irrestrito, distribuição e reprodução em qualquer meio, desde que a obra original seja devidamente citada. 